\title{
A Rare Case of Bilaterally Transposed Maxillary Supernumerary Premolars and its Management
}

\author{
${ }^{1}$ Loganathan Kavitha, ${ }^{2}$ Gopal S Narayan, ${ }^{3}$ Sivanesan K Rajavalli, ${ }^{4} \mathrm{~V}$ Kasim Shakeel Ahmed , ${ }^{5}$ Sabarimurugesan, \\ ${ }^{6}$ Veni A Baskara
}

\begin{abstract}
Supernumerary teeth also known as hyperdontia is a developmental abnormality characterized by the presence of extra teeth in addition to teeth of the normal eruption series. Non-syndromic supernumerary teeth have a site predilection for the mandibular premolar region. Herein, we report a rare case of non-syndromic, bilaterally transposed maxillary supernumerary premolar in a 29 -year-old male patient. Clinical considerations and various treatment options are also discussed.
\end{abstract}

Keywords: Non-syndromic, Occlusion, Supernumerary premolars, Transposition.

How to cite this article: Kavitha L, Narayan GS, Rajavalli SK, Ahmed VKS, Sabarimurugesan, Baskara VA. A Rare Case of Bilaterally Transposed Maxillary Supernumerary Premolars and its Management. J Oper Dent Endod 2018;3(2):92-96.

Source of support: Nil

Conflict of interest: None

\section{INTRODUCTION}

Supernumerary teeth or hyperdontia is a condition characterized by any teeth or tooth substance in excess of the usual configuration of 20 deciduous and 32 permanent teeth. ${ }^{1}$ These teeth may be single or multiple, unilateral or bilateral, erupted or impacted, and in one or both jaws. ${ }^{2}$

Supernumerary tooth are more commonly located in the maxillary midline, where they are referred to as mesiodens, representing $80 \%$ of the supernumerary teeth. ${ }^{3}$ The most common supernumerary teeth are the mesiodens followed by maxillary fourth molars or distomolars, maxillary paramolars, mandibular premolars,

${ }^{1}$ Senior Lecturer, ${ }^{2,5}$ Reader, ${ }^{3}$ Dental Practitioner, ${ }^{4,6}$ Professor

${ }^{1}$ Department of Oral and Maxillofacial Pathology, Ragas Dental College and Hospital, Uthandi, ECR, Chennai, Tamil Nadu, India

2,5,6 Department of Conservative and Endodontics, Ragas Dental College and Hospital, Chennai, Tamil Nadu, India

${ }^{3}$ Rajavalli's Dental Care, Thiruvanmiyur, Chennai, Tamil Nadu, India

${ }^{4}$ Department of Orthodontics, Ragas Dental College and Hospital, Chennai, Tamil Nadu, India

Corresponding Author: Loganathan Kavitha, Senior Lecturer, Department of Oral and Maxillofacial Pathology, Ragas Dental College and Hospital, Uthandi, ECR, Chennai, Tamil Nadu, India, Phone: 9710936767, e-mail: kavithalogie@gmail.com maxillary lateral incisors and mandibular fourth molars in the order of frequency of occurrence. Upper premolars, upper and lower canines and lower incisors rarely occur as supernumeraries. ${ }^{4}$ Supernumerary teeth occur between 0.3 to $1.9 \%$ in primary dentition and 0.1 to $3.6 \%$ in permanent dentition. ${ }^{5}$ Single supernumeraries are observed in 76 to $86 \%$ of cases, double supernumeraries occur in 12 to $23 \%$ of the cases and multiple supernumerary teeth are seen in less than $1 \%$ of cases. ${ }^{6}$

Supernumerary teeth can be classified in terms of chronology, topography, morphology, orientation and time of abnormal proliferation of dental lamina. Supernumerary tooth can be predeciduous (develop before deciduous teeth) or permanent (develop simultaneous to permanent teeth or after them). On the basis of morphology, supernumerary teeth can be defined as supplemental (eumorphic, with similar morphology to normal tooth), rudimentary (including conic shape, tuberculate, molariform, and odontome). Topographically, based on the site of occurrence in the dental arch they are categorized as mesiodens (between the incisors), paramolar (buccal or lingual to the molars), distomolar (behind the molars), and parapremolar (buccal or lingual to the premolar). Supernumerary teeth can also be classified as vertical, inverted and transverse according to orientation. Three types of supernumerary teeth are described in the literature depending on the time of abnormal proliferation of the dental lamina: predeciduous type, pre-permanent type (when it occurs before development of permanent tooth - more frequent type), and postpermanent type (when it develops after the deciduous and permanent follicles have been formed). ${ }^{7}$

We report a rare case of transposed, bilateral maxillary supernumerary premolars with deep caries erupted in occlusion. Various treatment options and management are discussed.

\section{CASE DESCRIPTION}

A 29 years male patient reported to the clinic with chief complaint of pain in the maxillary right and left posterior tooth region (Fig. 1). Clinical examination revealed two supernumerary premolars transposed between the first and the second maxillary molars. The patient complained of pain on mastication and extreme sensitivity to thermal changes in both the supernumerary premolar. The right supernumerary 
premolar between 16 and 17 had a broken amalgam restoration and the left supernumerary premolar between 26 and 27 had a deep carious lesion. Both the supernumerary premolars were tender on percussion. Periodontal probing depths were within the normal limits. To relieve the pain, old restoration was removed on the right premolar. Orthopantamogram was advised to evaluate the extent of the decay, morphology of the supernumerary teeth and to evaluate the presence of any other impacted supernumerary teeth (Fig. 2). Presence of single root in the supernumeraries was evident from the orthopantamogram. The right supernumerary premolar revealed a coronal radiolucency which was in close proximity to the pulp and the left one had a coronal radiolucency involving the pulp. The apical third of the root showed widening of periodontal lingament space in both the teeth suggestive of secondary caries with apical periodontitis in the right supernumerary tooth and dental caries with apical periodontitis in the left supernumerary tooth respectively. The orthopantamogram revealed impacted 18 and 28 with no other supernumeraries in the dentition. Presence of bilateral supernumerary premolars caused the distal inclination of second molars and thereby preventing the eruption of third molars which was evident from the orthopantamogram.

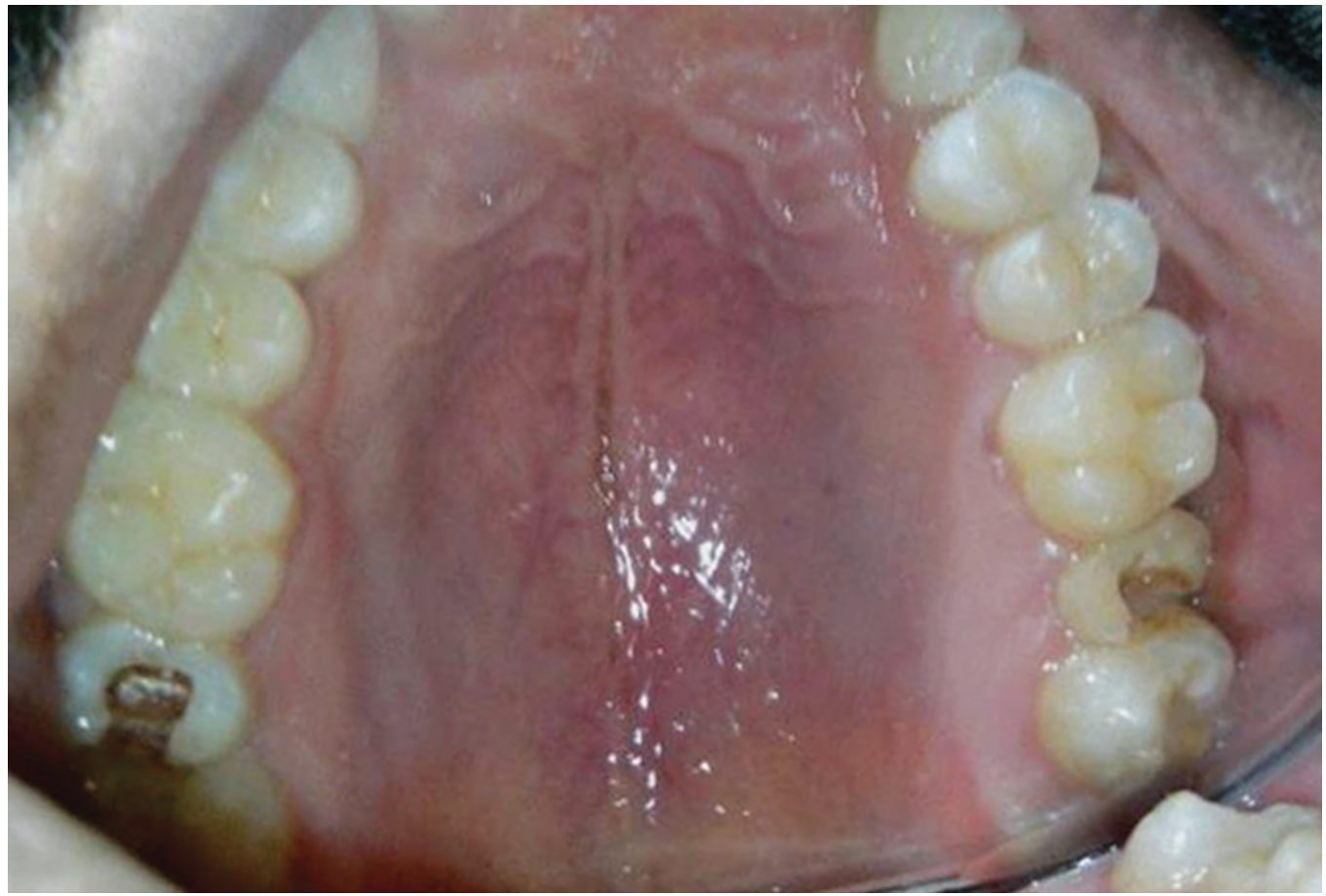

Fig. 1: Intraoral picture of maxillary arch showing the presence of transposed bilateral maxillary premolars in between the first and the second molar

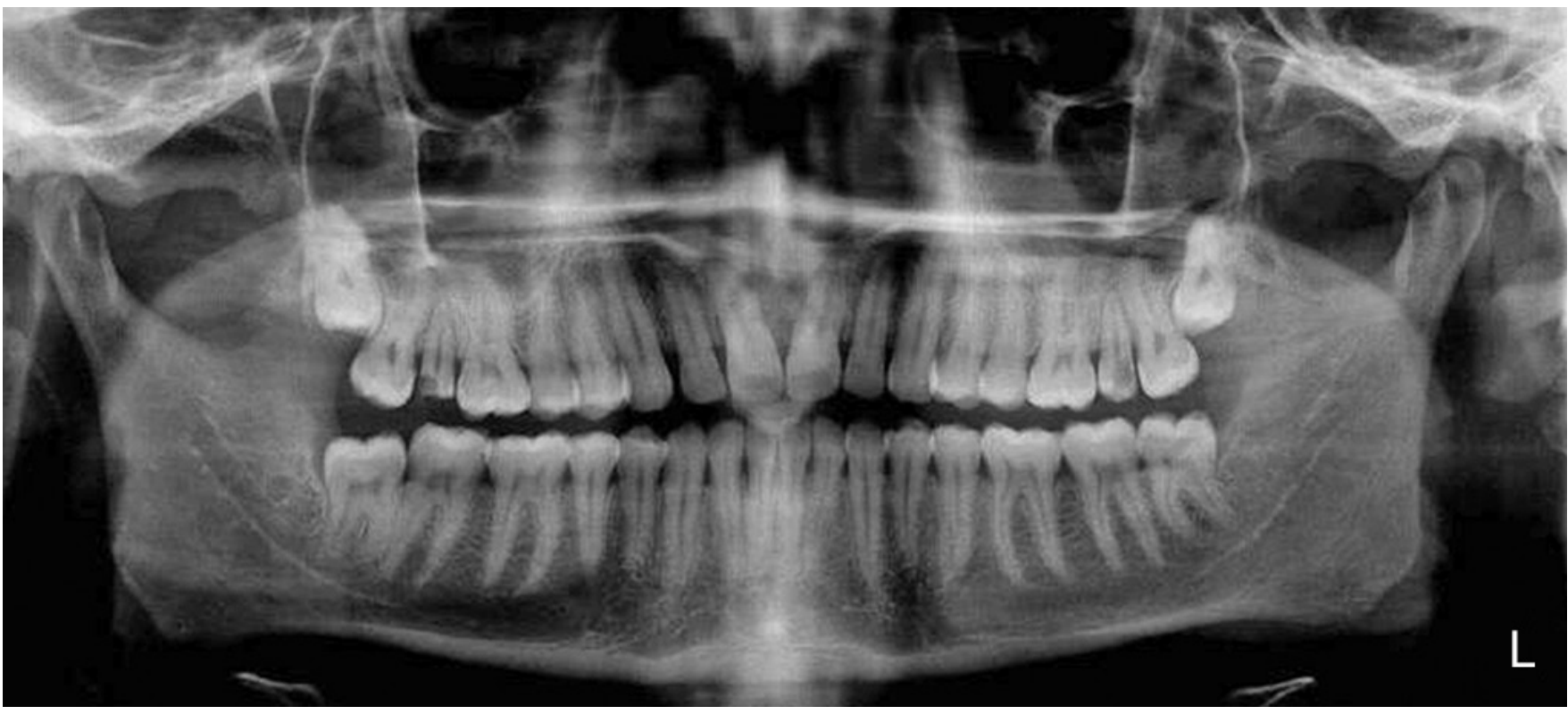

Fig. 2: Orthopantamogram revealing the presence of supernumerary premolars and impacted 18 and 28 in the maxillary arch 


\section{Management}

The following treatment options were considered and explained to the patient:

- Option 1: Management of bilateral maxillary supernumerary premolars endodontically and restoration, accepting the position of partially impacted maxillary third molars.

- Option 2: Extraction of bilateral maxillary transposed supernumerary premolars. Later extraction spaces can be utilized to mesialize maxillary second molars orthodontically, which might facilitate space for the partially impacted maxillary third molar to erupt bilaterally.

- Option 3: Extraction of bilateral maxillary transposed supernumerary premolars. Later extraction spaces can be restored either with osseo-integrated mini-implant with ceramic crown or three unit ceramic prosthesis, accepting the position of partially impacted maxillary third molar.

Patient was neither willing for extraction of the supernumeraries nor accepted for orthodontic treatment due to treatment duration involved or major prosthetic restoration due to economic reasons. Since patient had pain bilaterally, he preferred conservative management and restoration of both the transposed supernumerary teeth (Fig. 3).

Following dentition was observed clinically and radiographically,

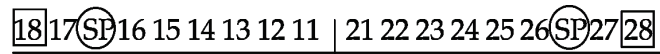

\begin{tabular}{ll|l}
4847464544434241 & 3132333435363738
\end{tabular}

1828 - Impacted third molar

(SP)- Supernumerary Premolar

\section{DISCUSSION}

Supernumerary premolars have been reported to represent 3 to $9 \%$ of all supernumerary teeth in the maxilla or mandible, and $75 \%$ occur in the mandible. The prevalence of supernumerary premolars ranges between 0.29 to $0.64 \%{ }^{8}$ Unlike our case, they frequently develop in the mandible than in the maxilla. ${ }^{9}$

Tooth transposition is a condition where there is a positional interchange of two teeth in the same quadrant, altering their normal position in the dental arch. ${ }^{10}$ Transposed supernumerary premolars erupted into occlusion are rarely reported in the literature. ${ }^{11-15}$ The present case report is unique in that the bilateral non-syndromic maxillary supernumerary premolars transposed between 1st and the 2nd molars were in function and occlusion. Besides being transposed, both the supernumerary premolars also had deep carious lesion.

Supernumerary teeth are usually associated with Gardener's syndrome, cleidocranial dysplasia, trichorhinophalangeal syndrome, cleft lip and cleft palate. Nonsyndromic supernumerary premolars are rare. Unlike the present case, majority of the non-syndromic supernumerary premolars occur in mandible, especially mandibular anterior region. ${ }^{2,16}$

Etiologically the occurrence of supernumerary teeth has not been yet elucidated. Several hypotheses have been proposed to explain the etiology of supernumerary teeth. These include phylogenetic theory of atavism (evolutionary throwback-reversion to the ancestery/ human dentition), dichotomy theory (single tooth bud is cleaved into two homologous or heterologous parts), morphogenetic field theory, and hereditary (an autosomal dominant trait, sex-linked inheritance). ${ }^{2,5}$ Review of literature strengthens the fact that supernumerary teeth have a strong hereditary component, without following a simple Mendelian pattern. It is also reported that Asian population is more affected with supernumeraries than others. ${ }^{15}$ According to Gardiner, post-permanent supernumerary teeth develop from the proliferation of the dental lamina after the permanent dentition is completed. ${ }^{17}$
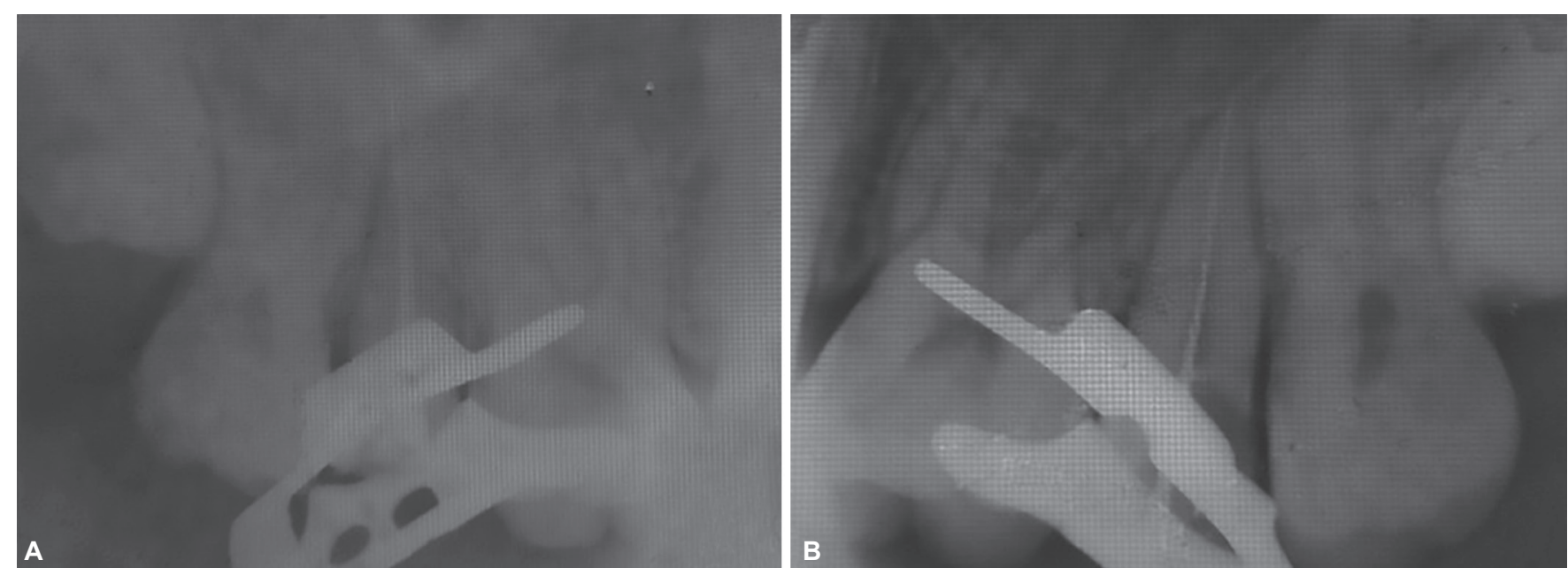

Figs $3 A$ and $B$ : Endodontically treated right $(A)$ and left; $(B)$ maxillary supernumerary premolars 
It is widely accepted that localized, independent, and conditional hyperactivity of dental lamina results in the development of supernumerary teeth. The symmetrical bilateral development in our case as well as in reviewed literature indicates that other factors also contribute to the development of supernumerary teeth in addition to localized hyperactivity of dental lamina. Thus, the supernumerary teeth presents with multiple etiological involving a combination of environmental and genetic factors. $^{18}$

The etiology of transposition is unclear. Transposition of dental anlage during development, migration of a tooth during eruption, heredity and trauma are some of the theories proposed to explain the phenomenon of transposition. ${ }^{19}$ Barnett reported a case with supernumerary premolars erupted buccally and lingually between the first and second molars in the maxilla and mandible respectively. ${ }^{20}$ Lin reported cases with supplemental teeth distal to the maxillary first permanent molars which were displaced bucally and not in occlusion. ${ }^{21}$ Vijayavergia et al. reported a case of two bilaterally functioning supernumerary transposed premolars present distal to the permanent maxillary first molars in normal occlusion. ${ }^{11}$ Ngeow, Means and Tabeling reported another case of a unilateral transposed supernumerary premolar aligned in occlusion. ${ }^{14,15}$

Supernumerary premolars are usually asymptomatic. Occasionally supernumerary teeth may lead to problems like crowding, impaction or delayed eruption or rotation of adjacent permanent teeth, retained deciduous teeth, abnormal eruption sequence, root resorption of adjacent teeth, cystic changes and compromised space closure. ${ }^{16}$

When supernumerary and transposed teeth are not in alignment (either buccually or palatally placed), they can result in displacement of the adjacent tooth leading to crowding, trauma to the surrounding structure, difficulty in speech and mastication. The teeth adjacent to the supernumerary teeth may be tipped, rotated or in infra occlusion. Endodontic management was considered appropriate in this case as the bilateral maxillary supernumerary premolars transposed between 1st and 2nd molars were aligned in occlusion without affecting the supporting structures and the adjacent teeth. Vora et al. has also reported a case of transposed bilateral maxillary supernumerary premolar that was endodontically managed using cone-beam computerized tomography to evaluate the root canal morphology of supernumerary premolars. ${ }^{22}$ The cause for the occurrence of dental caries in both the supernumerary premolars remains speculative.

Treatment planning should be considered on weighing the pathological sequelae of supernumerary teeth.
Extraction of asymptomatic supernumerary teeth should be indicated if any complications are evident. Periodic radiographic evaluation following extraction is advised to exclude any recurrence of supernumerary premolar.

\section{CONCLUSION}

Non-syndromic, bilaterally transposed supernumerary premolar occurring in the maxilla aligned in occlusion and in function as seen in the present case is rare. This case report highlights the importance of various management protocols that can be considered while treating transposed supernumerary teeth with dental caries and apical periodontitis. Endodontic management of these supernumeraries with deep carious lesion was considered appropriate as both the supernumerary premolars were aligned in occlusion and were functional. It will be prudent to appropriately follow-up the supernumerary teeth with panoramic radiograph to exclude any further complications.

\section{REFERENCES}

1. Schulze C. Developmental abnormalities of the teeth and jaws. In: Gorlin RJ, Goldman HM, eds. Thoma's Oral Pathology.6th ed. Vol. I. St Louis, Mo. CV Mosby; 1970: 112-122.

2. Farahani RM, Zonuz AT. Triad of bilateral duplicated permanent teeth, persistent open apex, and tooth malformation: A case report. J Contemp Dent Pract 2007 Nov;8:94-100.

3. Alaejos C, Contreras MA, Buenechea R, Berini L, Gay C. Mesiodens: A retrospectiva de una serie de 44 pacientes. Medicina Oral 2000;5:81-88.

4. Gay Escoda C, M Micas Mateos, Spain Tost A, Gargallo Albiol J. Other impacted teeth. Mesiodens and other supernumerary teeth. Supernumerary primary teeth. Including primary teeth. In: Gay Escoda C, Aytes Berini L, editors. Treaty of Oral Surgery. Volume I. 1st ed. Madrid: Ergon; 2004:497-534.

5. Saini T, Keene JJ, Whetten J. Radiographic diagnosis of supernumerary premolars: Case reviews. J Dent Child 2002 May-Aug;69:184-190.

6. Rajab LD, Hamdan MAM. Supernumerary teeth: review of the literature and a survey of 152 cases. International Journal of Paediatric Dentistry 2002 Jul;12:244-254.

7. Abhishek P, Kundabala M, Marisha D, Mandakini M, and Manuel S. Management of supernumerary teeth. Journal of Conservative Dentistry 2011 Jul-Sep;14:221-224.

8. Grahnen H, Lindahl B. Supernumerary teeth in the permanent dentition: a frequency study. Odontol Rev 1961 Jul-Sep; 12:290-294.

9. Stafne EC. Supernumerary teeth. Dent Cosmos 1932 Sep; 74:653-659.

10. Mattos BSC, Carvalho JCM, Matusita M, Alves APPP. Tooth transposition - A literature review and a clinical case. Braz J Oral Sci. 2006 Jan-Mar; 16(5):953-957.

11. Vijayavergia NK, Dayal PK, Joshi MR. Bilateral functioning premolar-form supernumerary teeth distal to the maxillary permanent first molars. Journal of Dentistry 1977 Mar-Dec; 5:76-78. 
12. Barker BCW. Transposed third premolars in occlusion. Oral Surgery 1977 Aug; 44:165.

13. Raphael DM. Transposed supernumerary premolar. Oral Surgery 1978 Oct; 46:598.

14. Means DA, Tabeling N. Transposed supernumerary premolar in occlusion, Oral Surgery Oral Medicine Oral Pathology 1984 Sep; 58:367.

15. Ngeow WC. Transposed Supernumerary Premolar in Alignment - A Case Report; Annals Of Dentistry, 1996 Dec; 3: 67-72.

16. Yusof WZ. Non-syndrome multiple supernumerary teeth: Literature review. Journal of Canadian Dental Association 1990 Feb; 56:147-149.
17. Gardiner JH. Supernumerary teeth. Dent Pract. 1961 Oct; 12:63-73.

18. Wang Xiu-Ping and Fan Jiabing. Molecular Genetics of Supernumerary Tooth Formation. Genesis. 2011 Apr;49:261-277.

19. Joshi MR, Bhatt NA. Canine transposition. Oral Surgery Oral Medicine Oral Pathology 1971 Jan;31:49-54.

20. Barnett BS. A case of multiple supernumerary teeth. British Journal of Orthodontics 1974 Jun;1:217-218.

21. Lin TY. Seven supernumerary premolars: Report of a case. Br Dent J. 1967;123:437-438

22. Vora J, Meena N, Mehta D, Murthy CS. Endodontic Management of Maxillary Supplemental Premolar using Cone-Beam Computed Tomography. J Contemp Dent Pract 2012 Jan-Feb; 13:130-135. 